\title{
Aclimatização de mudas micropropagadas de abacaxizeiro ornamental em diferentes volumes de substrato ${ }^{(1)}$
}

\author{
GUILHERME VIEIRA DO BOMFIM ${ }^{(1)}$, ANA CRISTINA PORTUGAL PINTO DE CARVALHO ${ }^{(2)}$, FRED CARVALHO BEZERRA ${ }^{(3)}$, \\ BENITO MOREIRA DE AZEVEDO(2), THALES VINÍCIUS DE ARAÚJO VIANA ${ }^{(2)}$ e KÁRCIA MANOELA ARRUDA SILVA DE \\ OLIVEIRA $^{(3)}$
}

\begin{abstract}
Resumo
O abacaxizeiro ornamental (Ananas comosus var. erectifolius (L. B. Smith) Coppens e Leal) é uma planta que produz "flores" de rara beleza, apreciadas por consumidores do mundo inteiro. Atualmente, esta espécie ornamental ocupa a segunda posição no ranking de exportações de flores e plantas ornamentais do Estado do Ceará. Em função da alta demanda do mercado, as mudas são produzidas em escala comercial pela micropropagação, uma técnica da cultura de tecidos que possui cinco etapas importantes. Uma delas, a aclimatização, é uma fase crítica, pois costuma responder pelos altos índices de mortalidade e pelas baixas taxas de crescimento das plantas devido, principalmente, à carência de informações técnicas e científicas sobre o cultivo nessa etapa. Portanto, para minimizar esse problema e preencher a lacuna existente com informações práticas importantes sobre o adequado manejo da cultura, o presente trabalho teve como objetivo, avaliar o efeito de diferentes volumes de substrato na aclimatização de mudas micropropagadas de abacaxizeiro ornamental. A pesquisa foi realizada em um telado pertencente à Embrapa Agroindústria Tropical, situada no município de Fortaleza-CE ( $3^{\circ} 44^{\prime}$ ' S e $\left.38^{\circ} 33^{\prime} \mathrm{W}\right)$. As mudas contidas nos distintos recipientes foram cultivadas no substrato pó-de-coco verde com húmus de minhoca (3:1) e irrigadas por microaspersão com uma lâmina d'água de $3 \mathrm{~mm}$, aplicada duas vezes ao dia. As variáveis agronômicas avaliadas aos 83 dias após o transplantio foram o número de folhas, a maior largura da $3^{\text {a }}$ folha e o maior diâmetro da roseta e, após este período, as massas fresca e seca das partes aérea e radicular. O delineamento experimental foi o de blocos ao acaso, com quatro tratamentos e cinco repetições para as variáveis relacionadas com o desenvolvimento foliar, e quatro tratamentos e quatro repetições para as variáveis relacionadas com a produção de massa na planta. Os tratamentos foram constituídos por: tubete de 300 $\mathrm{cm}^{3}$; tubete de $180 \mathrm{~cm}^{3}$; bandeja de Isopor ${ }^{\circledast}$ de $40 \mathrm{~cm}^{3}$ célula $^{-1}$ e bandeja de Isopor ${ }^{\circledast}$ de $30 \mathrm{~cm}^{3}$ célula $^{-1}$. Todas as repetições continham oito plantas cada. Os resultados da pesquisa evidenciaram que os tubetes de $180 \mathrm{~cm}^{3}$ foram os recipientes mais eficientes na promoção do melhor desenvolvimento das mudas micropropagadas de abacaxizeiro ornamental.
\end{abstract}

Palavras-chave: Ananas comosus var. erectifolius, recipientes, pó-de-coco.

\section{Abstract}

\section{Acclimatization of ornamental pineapple micropropagated plants in different substrate volumes}

The ornamental pineapple (Ananas comosus var. erectifolius (L. B. Smith) Coppens e Leal) is a plant that produces "flowers" of rare beauty, appreciated by consumers of the whole world. Nowadays, this ornamental species occupies the second position in the ranking of flowers and ornamental plants exports of the Ceará State. Due to the high market demand, the plants are already produced in commercial scale through the micropropagation, a technique of the tissue culture with five important stages. One of them, the acclimatization, is a critical phase because it answers for the high death rate and low growth rates of the plants. This happens for lack of technical and scientific information about the cultivation in this stage. Therefore, in order to minimize this problem and fill out the existent gap with important information about the appropriate culture management, the objective of this work was to evaluate the effects of different substrate volumes in the acclimatization of ornamental pineapple micropropagated plants. The research was carried out in a greenhouse of the Embrapa Tropical Agroindustry located in Fortaleza, Ceará State ( $3^{\circ} 44^{\prime} \mathrm{S}$ and $\left.38^{\circ} 33^{\prime} \mathrm{W}\right)$. The seedlings were cultivated in the green coir dust substrate with wormcompost $(3: 1)$ and they were irrigated with a $3 \mathrm{~mm}$ water level twice a day. The tested agronomic variables were the number of leaves, the largest width of the 3rd leaf and the largest diameter of the rosette, at 83 days after the transplant, and root and shoot fresh/ dry masses. The experimental design was a randomized block with 4 treatments and 5 repetitions for the variables related to foliar development, and with 4 treatments and 4 repetitions for the variables related to production of plant mass. The treatments consisted of: $300 \mathrm{~cm}^{3}$ pots; $180 \mathrm{~cm}^{3}$ pots; tray Styrofoam ${ }^{\mathrm{TM}} \mathrm{of} 40 \mathrm{~cm}^{3} \cdot \mathrm{cell}^{-1}$ and tray Styrofoam ${ }^{\mathrm{TM}}$ of $30 \mathrm{~cm}^{3} \cdot \mathrm{cell}^{-1}$. Each one of all repetitions comprised 8 plants. Results evidenced the best development of ornamental pineapple micropropagated plants of when they were cultivated in $180 \mathrm{~cm}^{3}$ pots.

Key words: Ananas comosus var. erectifolius, containers, coir dust.

\footnotetext{
(1) Parte da Dissertação de Mestrado do primeiro autor, financiada pelo FUNDECI / BNB. Recebido para publicação em 27/10/2006 e aceito para publicação em 28/10/2007.

(2) Departamento de Engenharia Agrícola, DENA-UFC, Caixa Postal 12168 - 60455-970 - Fortaleza (CE).

(3) Embrapa Agroindústria Tropical - 60.511-110 - Fortaleza (CE).
} 


\section{INTRODUÇÃO}

O Ananas comosus var. erectifolius, conhecido até pouco tempo como Ananas lucidus Miller, é a variedade de abacaxizeiro mais conhecida e explorada como planta ornamental no Brasil. Essa bromélia, nativa da Amazônia, é uma planta tropical de hábito terrestre que se desenvolve em campo aberto sob forte luminosidade e em solos arenosos (CORREIA et al., 1999). De acordo com COPPENS d'EECKENBRUGGEe LEAL(2003), essa espécie caracteriza-se por suas folhas rígidas, eretas, sem espinhos e de coloração púrpura, e por frutos pequenos, cilíndricos e de coloração vermelha.

No Brasil, ela é cultivada principalmente no Ceará, que é o Estado que mais produz e exporta as plantas e as "hastes florais" para países como Holanda, Estados Unidos e Alemanha (SOUZA et al., 2004). Atualmente, o Ananas comosus var. erectifolius ocupa a segunda posição no ranking de exportações cearenses de flores e plantas ornamentais.

Devido à elevada demanda do mercado, a maioria das mudas já é produzida por micropropagação, uma técnica da cultura de tecidos que, segundo TORRES et al. (1998), permite a obtenção de plantas em escala comercial, com elevada qualidade genética e fitossanitária, e em curto espaço físico e de tempo. A micropropagação se divide em cinco etapas importantes, uma delas, a aclimatização, que significa a passagem da planta do laboratório (in vitro) para um ambiente de cultivo (ex vitro), é considerada uma fase crítica e representa, em muitos casos, o principal gargalo na micropropagação de muitas espécies (HAZARIKA, 2003).

Entre os vários fatores que podem influenciar a aclimatização de mudas micropropagadas, os tipos de recipiente, nesse caso, os volumes de substrato, são muito importantes, uma vez que a quantidade de substrato é um fator que possui relação direta com desenvolvimento vegetal e com os custos de produção (MACEDO, 1993). Os recipientes proporcionam um meio para suportar e nutrir as plantas; oferecem uma conformação vantajosa para as raízes das mudas (FONSÊCA, 2001); fornecem uma melhor utilização do espaço do meio de cultivo; facilitam o plantio e os tratos culturais, como irrigação, desbaste, controle fitossanitário, etc. (BEZERRA, 2003) e maximizam a sobrevivência no campo (FONSÊCA, 2001). Ademais, o tamanho do recipiente influencia diretamente no custo final da muda, já que daí resulta a quantidade de substrato a ser utilizada, o espaço que irá ocupar no local de cultivo, a mão-de-obra utilizada no transporte, a remoção para a aclimatização e a retirada para a entrega ao produtor, além da influência na quantidade de insumos que irá necessitar (QUEIROZ e MÉLEM JÚNIOR, 2001). Apesar dessa importância, não existem pesquisas relacionadas com o manejo de recipientes durante a aclimatização de mudas micropropagadas de Ananas comosus var. erectifolius, de forma que as informações sobre o seu cultivo ainda são baseadas em experiências práticas dos próprios produtores. Este fato tem levado à baixa qualidade e/ou ausência de padronização dos produtos obtidos, logo, tem dificultado a comercialização de suas mudas.

Considerando a ausência de informações técnicas e científicas sobre o cultivo dessa espécie ornamental em recipientes com volumes diferenciados e, ainda, a grande importância econômica da cultura para o agronegócio da floricultura cearense, o presente trabalho teve como finalidade avaliar os efeitos de distintos volumes de substrato na aclimatização de mudas micropropagadas de abacaxizeiro ornamental.

\section{MATERIALEMÉTODOS}

O presente trabalho foi conduzido em um telado do tipo sombrite (50\% de sombreamento) pertencente à Embrapa Agroindústria Tropical (Figura 1), situada no município de Fortaleza (CE), com as coordenadas geográficas correspondentes a $3^{\circ} 44^{\prime}$ de latitude sul, $38^{\circ} 33^{\prime}$ de longitude oeste e 19,5 m de altitude acima do nível do mar.

O material vegetal utilizado consistiu de mudas micropropagadas in vitro de abacaxizeiro ornamental (Ananas comosus var. erectifolius). As mudas já devidamente desenvolvidas e enraizadas $( \pm 5 \mathrm{~cm}$ de altura com 4 a 5 folhas) foram transferidas para os seus respectivos recipientes, preenchidos com o substrato formado pela combinação pó-de-coco verde com húmus de minhoca na proporção volumétrica correspondente a três partes de pó-de-coco e uma parte de adubo.

Do início ao fim do experimento, as mudas foram irrigadas por um sistema de microaspersão suspenso, com a aplicação de uma lâmina correspondente a $3 \mathrm{~mm}$ de água, dividida em dois períodos do dia, pela manhã, às $9 \mathrm{~h} 30$ e à tarde, às $14 \mathrm{~h} 30$. As mudas de abacaxizeiro também receberam duas aplicações mensais com um litro $(1,56 \mathrm{ml}$ planta $^{-1}$ ) da solução nutritiva MS (MURASHIGE e SKOOG, 1962) diluída a $25 \%$ com a intenção de promover um incremento na taxa de crescimento das plantas.

As variáveis agronômicas avaliadas foram o número de folhas, a maior largura da terceira folha e o maior diâmetro da roseta, aos 83 dias após o transplantio, e as massas fresca e seca das partes aérea e radicular. $\mathrm{O}$ delineamento experimental foi o de blocos ao acaso com quatro tratamentos e cinco repetições para as variáveis relacionadas com o desenvolvimento foliar e quatro tratamentos e quatro repetições para as variáveis relacionadas com a produção de massa na planta. Todas as repetições continham oito plantas cada. Os tratamentos foram compostos por quatro tipos de recipientes, com distintas formas e capacidades volumétricas: tubete de 300 $\mathrm{cm}^{3}$ (TG), tubete de $180 \mathrm{~cm}^{3}$ (TP), bandeja de Isopor ${ }^{\circledR}$ de 40 $\mathrm{cm}^{3}$ célula $^{-1}$ (BG) e bandeja de Isopor ${ }^{\circledR}$ de $30 \mathrm{~cm}^{3}$ célula $^{-1}$ (BP), conforme Figuras 2 e 3 . Os dois tipos de tubete foram formados por material plástico do tipo polietileno rígido, de coloração preta, de formato cônico e afunilado, aberto na extremidade inferior e com pequenas estrias longitudinais (oito frisos). Diferiam entre si no diâmetro, na altura e, conseqüentemente, no volume suportado. Seus 
respectivos valores foram $6,5 \mathrm{~cm}, 20 \mathrm{~cm}$ e $300 \mathrm{~cm}^{3}$ para o TG e $5,3 \mathrm{~cm}, 13 \mathrm{~cm} \mathrm{e} 180 \mathrm{~cm}^{3}$ para o TP(Figura3). As duas bandejas de Isopor ${ }^{\circledR}$ foram constituídas de poliestireno expandido, de coloração branca e com células de formato piramidal invertida, abertas na extremidade inferior. A BG tinha $68 \mathrm{~cm}$ de comprimento, $34 \mathrm{~cm}$ de largura e 128 células, cada uma, com $6 \mathrm{~cm}$ de profundidade, $3,5 \mathrm{~cm}$ de largura e $40 \mathrm{~cm}^{3}$ de volume. Já a BP tinha $68 \mathrm{~cm}$ de comprimento, 34 cm de largura e 288 células, estas, com profundidade de 6,0 $\mathrm{cm}$, largura de $2,5 \mathrm{~cm}$ e volume de $30 \mathrm{~cm}^{3}$, cada.

Os dados das variáveis foram submetidos a uma análise de variância pelo método dos polinômios ortogonais. Quando significativos esses dados foram comparados pelo teste de Tukey ao nível de $5 \%$ de probabilidade para verificar a existência de alguma diferença significativa entre os tratamentos.

\section{RESULTADOS}

Os valores médios das variáveis relacionadas com o desenvolvimento foliar, avaliados em função dos diferentes volumes de substrato, aos 83 DAT, estão contidos na Tabela 1. De acordo com os resultados (Tabela 1), todas as variáveis foram influenciadas pelos diferentes volumes de substrato.

Para a variável número de folhas (Tabela 1), observa-se que os maiores valores foram proporcionados por ambos os tipos de tubetes, enquanto os menores, pelas duas bandejas. O maior valor numérico da variável, proporcionado pelo tubete grande, diferiu significativamente dos dois menores valores, obtidos com a utilização de ambas as bandejas. Com isso, o número de folhas obtido com a utilização do tubete grande foi 12,83 e $16,31 \%$ maior em relação ao número de folhas obtido pelas bandejas grande e pequena, respectivamente.

Em relação a maior largura da $3^{\mathrm{a}}$ folha (Tabela 1 e Figura 4), nota-se que existiu diferença significativa entre o maior valor da variável e os dois menores valores da mesma, obtidos com o emprego dos respectivos tubetes grandes e, bandejas grande e pequena. Para essa variável, o tubete grande proporcionou um desenvolvimento 12,28 e $17,99 \%$ superior àquele proporcionado pelas bandejas grande e pequena, respectivamente. Outra diferença significativa ocorreu entre os valores resultantes do uso do tubete pequeno e da bandeja pequena. Nesse caso, o tubete pequeno propiciou a maior largura da $3^{\mathrm{a}}$ folha 11,86 $\%$ superior ao proporcionado pela bandeja pequena.

Analisando ainda os resultados (Tabela 1), percebe-se que os dois maiores e menores valores da variável maior diâmetro da roseta (Figura 5), resultantes do uso dos dois tipos de tubetes e de ambas as bandejas, respectivamente, tiveram diferença significativa entre si. Ambos os tipos de tubetes, comparados às duas bandejas, promoveram o desenvolvimento dessa variável, em média, $18,05 \%$ superior.

Os valores médios das variáveis relacionadas com a produção de massas fresca e seca das plantas, analisados em função dos diferentes tipos de recipientes, constam na Tabela 2 . Por essa tabela, percebe-se que todas as variáveis foram influenciadas pelos distintos volumes de substrato.

Tabela 1. Valores médios das variáveis número de folhas (NF), maior largura da $3^{\mathrm{a}}$ folha (MLF) e maior diâmetro da roseta (MDR) de abacaxizeiro ornamental (Ananas comosus var. erectifolius), aos 83 dias após o transplantio das mudas, de acordo com os recipientes tubete grande (TG), tubete pequeno (TP), bandeja grande (BG) e bandeja pequena (BP), Fortaleza (CE), 2005.

Table 1. Averages values of the variables number of leaves (NF), largest width of the 3rd leaf (MLF) and largest diameter of the rosette (MDR) of ornamental pineapple (Ananas comosus var. erectifolius), at 83 days after the transplant of seedlings, according to the large pots (TG), small pots (TP), large tray (BG) and small tray (BP), Fortaleza-CE, 2005.

\begin{tabular}{cclc}
\hline Tratamento & NF & MLF $(\mathrm{cm})$ & MDR $(\mathrm{cm})$ \\
\hline TG & $18,70 \mathrm{a}$ & $2,02 \mathrm{a}$ & $10,10 \mathrm{a}$ \\
TP & $17,50 \mathrm{ab}$ & $1,88 \mathrm{ab}$ & $9,25 \mathrm{a}$ \\
BG & $16,30 \mathrm{~b}$ & $1,77 \mathrm{bc}$ & $7,93 \mathrm{~b}$ \\
BP & $15,65 \mathrm{~b}$ & $1,65 \mathrm{c}$ & $7,92 \mathrm{~b}$ \\
CV $(\%)$ & 6,08 & 4,52 & 6,09 \\
DMS $(5 \%)$ & 11,42 & 8,48 & 11,43 \\
\hline
\end{tabular}

Médias seguidas de mesma letra nas colunas não diferem entre si pelo teste de Tukey a $5 \%$.

Averages followed by same letter in the columns don't differ themselves by the Tukey test at $5 \%$.

Tabela 2. Valores médios das variáveis relacionadas com a produção de massas fresca e seca na parte aérea (PA) e no sistema radicular (SR) das mudas de abacaxizeiro ornamental (Ananas comosus var. erectifolius), de acordo com os recipientes tubete grande (TG), tubete pequeno (TP), bandeja grande (BG) e bandeja pequena (BP), Fortaleza (CE), 2005.

Table 2. Averages values of the variables related to production of fresh/dry masses in shoot part (PA) and root part (SR)of seedlings of ornamental pineapple (Ananas comosus var. erectifolius), according to the large pots (TG), small pots (TP), large tray (BG) and small tray (BP), Fortaleza-CE, 2005.

\begin{tabular}{cccccc}
\hline Tratamento & Massa fresca & Fresh mass & & Massa seca & Dry mass \\
\cline { 2 - 3 } \cline { 5 - 6 } Treatment & PA $(\mathrm{g})$ & SR $(\mathrm{g})$ & & PA $(\mathrm{g})$ & SR $(\mathrm{g})$ \\
\hline TG & $8,999 \mathrm{a}$ & $0,211 \mathrm{a}$ & & $0,846 \mathrm{a}$ & $0,048 \mathrm{a}$ \\
TP & $8,924 \mathrm{a}$ & $0,196 \mathrm{a}$ & & $0,810 \mathrm{a}$ & $0,038 \mathrm{a}$ \\
BG & $5,379 \mathrm{~b}$ & $0,100 \mathrm{~b}$ & & $0,470 \mathrm{~b}$ & $0,023 \mathrm{~b}$ \\
BP & $3,965 \mathrm{~b}$ & $0,071 \mathrm{~b}$ & & $0,335 \mathrm{~b}$ & $0,020 \mathrm{~b}$ \\
CV $(\%)$ & 12,82 & 28,58 & & 18,27 & 16,59 \\
DMS $(5 \%)$ & 28,34 & 63,16 & & 40,39 & 36,67 \\
\hline
\end{tabular}

Médias seguidas de mesma letra nas colunas não diferem entre si pelo teste de Tukey a $5 \%$.

Averages followed by same letter in the columns don't differ themselves by the Tukey test at $5 \%$. 
Nota-se (Tabela 2) que os valores médios de todas as variáveis tiveram comportamento estatístico semelhantes. Dessa maneira, verifica-se que houve diferença significativa entre os dois maiores e os dois menores valores numéricos de todas as variáveis obtidos com o uso dos tubetes grande e pequeno e das bandejas grande e pequena, respectivamente. Então, para as variáveis relacionadas com a produção de massa na planta, os dois tipos de tubetes proporcionaram, em média, acúmulos de massa 47,86, 58,03, 51,35 e 49,36\% superiores aos acúmulos promovidos por ambas as bandejas.

\section{DISCUSSÃO}

Os resultados adquiridos com a análise das variáveis, aos 83 DAT (Tabela 1), evidenciaram o melhor desenvolvimento foliar da cultura quando foram utilizados os recipientes de maior altura e capacidade volumétrica, ou seja, os dois tipos de tubetes. Corroborando com estes resultados, KEEVER e COBB (1985) verificaram na espécie ornamental azevim (Ilex aquifolium) que o maior desenvolvimento da planta foi atingido mediante o uso de recipientes de maior diâmetro e altura. Já ao analisarem outra espécie ornamental, a azaléia (Rhododendron simsii Planch.), os autores observaram que somente o aumento do diâmetro do recipiente promoveu o maior desenvolvimento cultura. VALLONE (2003), ao avaliar a produção de mudas de cafeeiro (Coffea arabica L.) em tubetes de polietileno de 50 e $120 \mathrm{~cm}^{3}$, também concluiu que as plantas produzidas em um maior volume de substrato tiveram maior desenvolvimento em relação às mudas produzidas em um menor volume.

Resultados similares aos deste experimento, com relação à produção de massa na planta (Tabela 2), foram obtidos por BRITO et al. (2004), quando avaliaram a produção de mudas de tomate de mesa (Lycopersicon esculentum Mill.) em bandejas de Isopor ${ }^{\circledR}$ e em tubetes de polietileno, pois os autores verificaram que a utilização dos tubetes foi significativamente superior a das bandejas em relação às matérias fresca e seca totais da parte aérea. SINDEAUX (2005), na aclimatização de mudas micropropagadas de bananeira (Musa spp.) em tubetes de 300 e $180 \mathrm{~cm}^{3}$ e em bandejas de 40 e $30 \mathrm{~cm}^{3}$ célula $^{-1}$, também constatou que os maiores acúmulos de massas fresca e seca das partes aérea e radicular foram proporcionados pelos tubetes, enquanto os menores acúmulos, pelas bandejas.

Os resultados obtidos com o experimento (Tabelas 1 e 2) demonstraram a superioridade dos tubetes grande e pequeno na promoção do desenvolvimento mais acentuado das partes vegetais analisadas. A razão para tal acontecimento pode estar relacionada com as características intrínsecas desses recipientes, como maior altura e capacidade volumétrica.

De acordo com INGRAM et al. (2003), a altura do recipiente determina a altura do substrato e, por conseguinte, espaço de aeração, ou seja, a disponibilidade de oxigênio. Segundo os autores, os recipientes de maior altura normalmente têm o maior volume de poros grandes (macroporos) preenchidos com ar, ou seja, uma maior disponibilidade de oxigênio às raízes. MIRZA (2006) ressalta que o oxigênio é essencial para os processos metabólicos que liberam energia para as funções vitais da planta e, também, para a absorção de nutrientes minerais. Portanto, no atual experimento, os recipientes de maior altura, nesse caso os tubetes, por terem um conteúdo relativo de água no substrato menor, provavelmente devem ter proporcionado um melhor espaço de aeração e, conseqüentemente, uma maior disponibilidade de oxigênio para o desenvolvimento mais adequado do sistema radicular.

A maior capacidade volumétrica de ambos os tipos de tubetes deve ter influenciado de maneira decisiva o desenvolvimento das mudas de abacaxizeiro ornamental ao longo da aclimatização. O maior volume de substrato contido nesses recipientes pode ter contribuído para a formação de um sistema radicular mais desenvolvido e de melhor arquitetura que, por sua vez, deve ter explorado mais eficientemente o substrato e absorvido maiores quantidades de nutrientes que se encontravam dissolvidos na solução do meio. WIEN (1997) explica que um maior volume de substrato restringe menos o desenvolvimento das raízes e ainda propicia-lhes uma maior porosidade, logo, melhores condições de aeração (oxigênio). $\mathrm{O}$ autor também ressalta que maiores volumes de substrato, em comparação aos menores volumes, têm maior disponibilidade de água e nutrientes. Inúmeros experimentos, realizados com diversas espécies vegetais, demonstram que os recipientes de maior capacidade volumétrica produzem mudas mais desenvolvidas e de melhor qualidade. Como exemplos, têmse os trabalhos de SINDEAUX (2005), com mudas micropropagadas de bananeira (Musa spp.); TELLES et al. (2005), com mudas de cravo-de-defunto (Tagetes patula I.); KEEVER e COBB (1985), com mudas de azevim (Ilex aquifolium) e azaléia (Rhododendron simsii), entre outros.

Outro fator que pode ter influenciado positivamente o desenvolvimento geral da planta nos dois tipos de tubetes foi, provavelmente, a menor perda dos nutrientes presentes no substrato através da lixiviação. Como a altura desses recipientes é relativamente elevada, a lixiviação dos nutrientes deve ter apenas transportado os mesmos para regiões abaixo, mas ainda próximas do sistema radicular.

Os resultados desse experimento evidenciaram que ambas as bandejas, ao contrário dos tubetes, promoveram o desenvolvimento menos pronunciado do abacaxizeiro, tanto da parte foliar como do sistema radicular. O menor desenvolvimento da cultura nas bandejas pode, provavelmente, estar associado a fatores relacionados com o menor volume e altura das células e com a competição entre as plantas.

DRZAL et al. (1999) relatam que a altura do recipiente limita a altura do substrato e esta, a capacidade do recipiente que, por sua vez, determina o espaço de aeração. Nesse aspecto, FERMINO (2002) afirma que os 
recipientes de dimensões reduzidas, por terem uma pequena altura de substrato, dificultam a drenagem, aumentam a capacidade de retenção de água e, dessa forma, promovem o encharcamento do meio. Nas mudas de abacaxizeiro ornamental, a reduzida altura das bandejas pode ter dificultado a drenagem, elevado o conteúdo relativo de água nas células e, com isso, ter causado problemas relacionados com o excesso d'água, principalmente, no que diz respeito a inadequada oxigenação do substrato. A insuficiente oxigenação em um meio pode reduzir o processo fotossintético (VAN'T WOUDT e HAGAN, 1967) e dificultar severamente a atividade respiratória (CLARK e KEMPER, 1967), então, podem provocar a redução no desenvolvimento do vegetal.

É provável que a reduzida capacidade volumétrica das células tenha sido o fator que mais limitou o desenvolvimento das mudas. BEZERRA (2003) salienta que recipientes volumetricamente pequenos reduzem $o$ desenvolvimento vegetal, por restringirem fisicamente o sistema radicular das plantas. A restrição radicular, de acordo com alguns trabalhos, pode reduzir o crescimento das raízes (LEAL et al., 2005), da área foliar (IERSEL, 1997) e da produção de biomassa (SINDEAUX, 2005). Isso acontece porque a restrição radicular afeta, entre outros fatores, a fotossíntese, a respiração, o teor de clorofila nas folhas, as relações de água na planta e a absorção de nutrientes (NESMITH e DUVAL, 1998).

As reduzidas altura e capacidade volumétrica das bandejas ainda podem ter contribuído para a maior perda dos nutrientes presentes no substrato pelo processo de lixiviação. Portanto, é bem provável que aplicação da lâmina d'água tenha umedecido rapidamente todo o substrato e, com isso, tenha provocado o escoamento mais intenso da água e o carreamento dos nutrientes nela diluídos para fora das células, nesse caso, para a superfície do solo abaixo das bandejas. CARNEIRO (1995) salienta que em recipientes de reduzida dimensão, devido ao pequeno volume de substrato presente, o processo de lixiviação ocorre rapidamente, carregando consigo os íons fertilizantes.

Outro fator que também pode ter contribuído para o menor desenvolvimento das mudas cultivadas nas bandejas foi o menor espaçamento entre as plantas. Devido às reduzidas dimensões de cada célula, as mudas cresceram muito próximas umas das outras, e essa condição acabou provocando uma sobreposição foliar entre as plantas. Em suma, essa sobreposição pode ter gerado uma competição por luz, água e nutrientes (solução nutritiva), na qual algumas plantas podem ter sido beneficiadas (mais desenvolvidas) em detrimento de outras. DUARTE et al. (2002) reportam que a altura da planta e a área foliar podem influenciar a capacidade competitiva de determinadas plantas, reduzindo a penetração de luz e, conseqüentemente, a produção. Sob insuficiência luminosa, há menor eficiência fotossintética, logo, menor fixação de $\mathrm{CO}_{2}$ atmosférico por parte das folhas (ZANINE e SANTOS, 2004). Em relação à competição por água e nutrientes, a maioria dos trabalhos enfatiza que a mesma ocorre principalmente em nível de subsolo, ou seja, em nível radicular. Nesse experimento, como as folhas do abacaxizeiro são dotadas das habilidades singulares de acumular água na roseta (CARVALHO, 2002) e de absorver água e nutrientes através de pêlos (PAULA, 2000), é conveniente considerar que os efeitos negativos desse tipo de competição também podem ter prejudicado o desenvolvimento normal das plantas. Levando-se em conta isso, pode-se deduzir que as plantas mais desenvolvidas, neste caso, melhor supridas de luz, água e nutrientes devem ter limitado o crescimento daquelas que não receberam os fatores de produção nas mesmas proporções.

A partir dos resultados obtidos nesse experimento, pôde-se verificar que, em termos estatísticos, não houve diferença entre os valores das variáveis com o uso de ambos os tubetes. O mesmo ocorreu com as duas bandejas. Essa situação ocorreu, possivelmente, em função da pequena diferença entre os volumes de cada tipo de recipiente (bandejas), e pelo fato de a cultura ter um crescimento relativamente mais lento (tubetes). Nesse sentido, BARNABÉ et al. (1994) ao avaliarem o efeito de três tipos de bandejas de Isopor $^{\circledR}$ (128, 200 e 228 células) na produção de mudas de pimentão (Capsicum annuиm L.), também verificaram que as massas fresca e seca das partes aérea e do sistema radicular não diferiram estatisticamente nas mudas produzidas nas bandejas de 128 e 200 células, ou seja, concluíram que não houve diferença estatística entre as plantas cultivadas em recipientes com capacidades volumétricas similares. KEEVER e COBB (1987), por sua vez, salientam que as espécies de crescimento rápido são as mais beneficiadas com os maiores volumes de substrato e altos níveis de fertilizante. Portanto, mesmo em recipientes com capacidades volumétricas bastante diferenciadas, as plantas de crescimento lento podem ter desenvolvimento semelhante. $\mathrm{O}$ abacaxizeiro, em comparação com certos tipos de plantas, pode ser considerado como uma planta de crescimento lento. RAVEN et al. (2001) explica que as plantas com o metabolismo ácido das crassuláceas (CAM ou MAC), por economizarem água pelo fechamento estomático diurno, diminuem consideravelmente a sua capacidade de fixar $\mathrm{CO}_{2}$. Em função disto, as plantas CAM crescem vagarosamente quando comparadas com as plantas de metabolismo C3 e C4, principalmente, em condições outras do que a de extrema aridez. Isso justifica porque o tempo de aclimatização do abacaxizeiro ornamental é relativamente prolongado.

Nesta pesquisa, ficou claro que os tubetes grande e pequeno foram os tipos de recipientes que proporcionaram a obtenção de mudas mais vigorosas e de melhor qualidade. Comparando os valores médios das variáveis, alcançados com o uso de ambos os tubetes, pôde-se observar que, em termos numéricos, o tubete grande se mostrou sempre superior ao tubete pequeno nas ocasiões estudadas. Apesar disso, estatisticamente, não ocorreu nenhuma diferença significativa entre eles. Dessa forma, pode-se deduzir que o uso do tubete pequeno é mais vantajoso, já que o emprego de recipientes com capacidades volumétricas relativamente reduzidas proporciona uma redução dos custos de produção 
(GODOY e CARDOSO, 2005), em decorrência dos menores gastos com substrato, transporte, distribuição e plantio (GONZALES, 1988). Também, ao se levar em conta que as partes aérea e radicular das plantas cultivadas nos dois tipos de tubetes estavam bem-desenvolvidas e em perfeito estado, é possível que a aclimatização com o uso do tubete pequeno proporcione desempenho da planta em campo, semelhante àquele que seria obtido com o uso do tubete grande. Portanto, o emprego do tubete grande só seria vantajoso quando os custos envolvidos na sua aquisição e/ou no processo produtivo não representassem um fator limitante a sua utilização, ou ainda, quando o período de permanência das mudas nos recipientes fosse muito elevado.

Diante do exposto, conclui-se que as mudas micropropagadas de abacaxizeiro ornamental (Ananas comosus var. erectifolius) podem ser aclimatizadas na região litorânea do Estado do Ceará, em telado, com tubetes de $180 \mathrm{~cm}^{3}$.

\section{REFERÊNCIAS}

BARNABÉ, J.; GIORGETTI, J. R.; GOTO, R. Influência de três tipos de bandejas para produção de mudas de pimentão. Horticultura Brasileira, Brasília, v. 18, suplemento, p. 71, 1994.

BEZERRA, F. C. Produção de mudas de hortaliças em ambiente protegido. Fortaleza: Embrapa Agroindústria Tropical, 2003. 22 p. (Documentos, 72).

BRITO, F. M. de; MOTA, W. F. da; SOUZA, A. S.; SILVEIRA, E. K. C. P. Produção de mudas de tomate de mesa em função da utilização de diferentes substratos em bandejas e tubetes. In: ENCONTRO NACIONAL SOBRE SUBSTRATO PARA PLANTAS, 4, 2004, Viçosa,. Resumos... Viçosa, UFV, 2004. p.322.

CARNEIRO, J. G. A. de. Importância da localização dos viveiros. In:___ (Org.). Produção e controle de qualidade de mudas florestais. Curitiba: UFPR/FUPEF, 1995. p.19.

CARVALHO, L. F. N. de. O cultivo da bromélia. Rio de Janeiro: TUJ, 2002. 32 p.

CLARK, F. E.; KEMPER, W. D. Microbiological activity in relation to soil water and soil aeration. In: HAGEN, R. M. et al. (Ed.). Irrigation of agricultural lands. Madison: American Society of Agronomy, 1967. p. 472-480.

COPPENS d'EECKENBRUGGE, G.; LEAL, F. Morphology, anatomy and taxonomy. In: BARTHOLOMEW, D. P.; PAULL, R. E.; ROHRBACH, K. G. (Ed.). The pineapple: botany, production and uses. Oxon: Cabi Publishing, 2003. p. 13-32.

CORREIA, D.; OLIVEIRA, P. M. A. de; RIBEIRO, K. A.; SILVEIRA, M. R. S. de. Avaliação da multiplicação in vitro do abacaxi ornamental (Ananas lucidus Miller). Fortaleza: EMBRAPA-CNPAT, 1999. 2 p. (Pesquisa em andamento, 56).
DRZAL, M. S.; CASSEL, P. K.; FONTENO, W. C. Pore exaction analysis: a new tool for substrate testing. Acta Horticulturae, Wageningen, v.1, n.481, p.47-53, 1999.

DUARTE, F. N.; DA SILVA, J. B.; SOUZA, F. I. Competição de plantas daninhas com a cultura do milho no município de Ijaci, MG. Ciências Agrotécnicas, Lavras, v.26, n.5, p. 983-992, 2002.

FERMINO, M. H. O uso da análise física na avaliação da qualidade de componentes e substratos. In: FURLANI, A. M. C. et al. Caracterização, manejo e qualidade de substratos para produção de plantas. Campinas: Instituto Agronômico, 2002. p. 29-37. (Documentos IAC, 70).

FONSÊCA, T. G. Produção de mudas de hortaliças em substratos de diferentes composições com adição de $\mathrm{CO}_{2}$ na água de irrigação. 2001, 72 f. Dissertação (Mestrado em Agronomia). Universidade de São Paulo, Piracicaba: ESALQ,2001.

GODOY, M. C.; CARDOSO, A. I. I. Produtividade da couve-flor em função da idade de transplantio das mudas e tamanhos de células na bandeja. Horticultura Brasileira, Brasília, v. 23, n. 3, p. 837-840, 2005.

GONZALES, R. A. Estudio sobre el comportamiento en viveiro de Pinus caribaea var. caribaea cultivado en envases de polietileno de 12 dimensiones diferentes. Revista Forestal Baracoa, La Habana, v.18, n.1, p.39-51, 1988.

HAZARIKA, B. N. Acclimatization of tissue-cultured plants. Current Science, Bangalore, v. 85, n.12, p. 1704$1712,2003$.

IERSEL, V. M. Root restriction effects on growth and development of salvia (Salvia splendens). HortScience, Alexandria, v.32, n.7, p.1186-1190, 1997.

INGRAM, D. L.; HENLEY, R. W.; YEAGER, T. H. Growth Media for Container Grown Ornamental Plants. Florida: University of Florida, 2003. 18 p. (Documents, 241).

KEEVER, G. J.; COBB, G. S. Effects of container dimension and on growth of three woody ornamentals. HortSciense, Alexandria, v. 20, n. 2, p. 276-278, 1985.

Effects of container volume and fertility rate on growth of two woody ornamentals. HortSciense, Alexandria, v. 22, n. 5, p. 891-893, 1987.

LEAL, P. L.; MARTINS, M. A.; RODRIGUES, L. A.; SCHIAVO, J. A. Crescimento de mudas micropropagadas de bananeira micorrizadas em diferentes recipientes. Revista Brasileira de Fruticultura, Jaboticabal, v. 27, n. 1, p. 84-87, 2005

MACEDO, A. L. Produção de mudas em viveiros florestais: espécies nativas. São Paulo: Fundação Florestal, 1993. $18 \mathrm{p}$.

MIRZA, M. Taking advantage of nutritional values of alberta grown vegetables. Alberta Agriculture, Food and Rural Development, Edmonton, v.5, n.1-2, p. 1-9, 2006.

MURASHIGE, T.; SKOOG, F. A. A revised medium for rapid growth and bioassay with tobacco tissue culture. Phisiologia Plantarum, Copenhagem, v. 25, n. 3, p. 473-497, 1962. 
NESMITH, D. S.; DUVAL, J. R. The effect of container size. HortTechnology, Alexandria, v. 8, n. 4, p. 495-498, 1998.

PAULA, C. C. Cultivo de bromélias. Viçosa: Aprenda Fácil, 2000.139p.

QUEIROZ, J. A.; MELÉM JÚNIOR, N. J. Efeito do tamanho do recipiente sobre o desenvolvimento de mudas de açaí (Euterpe oleracea Mart.). Revista Brasileira de Fruticultura, Jaboticabal, v.21, n.1, p.460-462, 2001.

RAVEN, P. H.; EVERT, R. F.; EICHHORN, S. E. Biologia vegetal. 6. ed. Rio de Janeiro: Guanabara Koogan, 2001. $906 \mathrm{p}$.

SINDEAUX, J. H. F. Aclimatização de mudas micropropagadas de bananeira em ambiente protegido em função do tipo e do volume do substrato e da lâmina e da frequiência de irrigação. 2005, 102 fl. Dissertação (Mestrado em Irrigação e Drenagem), Fortaleza: Universidade Federal do Ceará, UFC, 2005.

SOUZA, F. V. D.; SEREJO, J. A. dos S.; CABRAL, J. R. S. Beleza rara. Cultivar - Frutas e Hortaliças, Pelotas, v.5, n.28, p.7-8, 2004.
TELLES, C. A.; MIELKE, É. C.; MACHADO, M. P.; BIASI, L. A. Diferentes volumes de substrato no desenvolvimento de plantas de cravo-de-defunto (Tagetes patula I.). Revista Brasileira de Horticultura Ornamental, Campinas, v.11, n.1, p.67-71, 2005.

TORRES, A. C.; CALDAS, L. S.; BUSO, J. A. Cultura de tecidos e transformação genética de plantas. Brasília: EMBRAPA-CNPH, 1998. v.1, 864 p.

VALLONE, H. S. Produção de mudas de cafeeiro (Coffea arabica L.) em tubetes com polímero hidroretentor, diferentes substratos e adubações. 2003, 75f. Dissertação (Mestrado em Fitotecnia), Lavras: Universidade Federal de Lavras, UFL, 2003.

VANT'T WOUDT, B. D.; HAGAN, R. M. Crop responses at excessively high soil moisture levels. In: LUTHIN, J. N. (Ed.). Drainage of agricultural lands. Madison: American Society of Agronomy, 1967. p. 514-578.

WIEN, H. C. The physiology of vegetable crops. Oxon: CABI Publishing, 1997. $662 \mathrm{p}$.

ZANINE, A. de M.; SANTOS, E. M. Competição entre espécies de plantas - uma revisão. Revista da Faculdade de Zootecnia, Veterinária e Agronomia, Uruguaiana, v. 11, n. 1,p. 103-122, 2004.

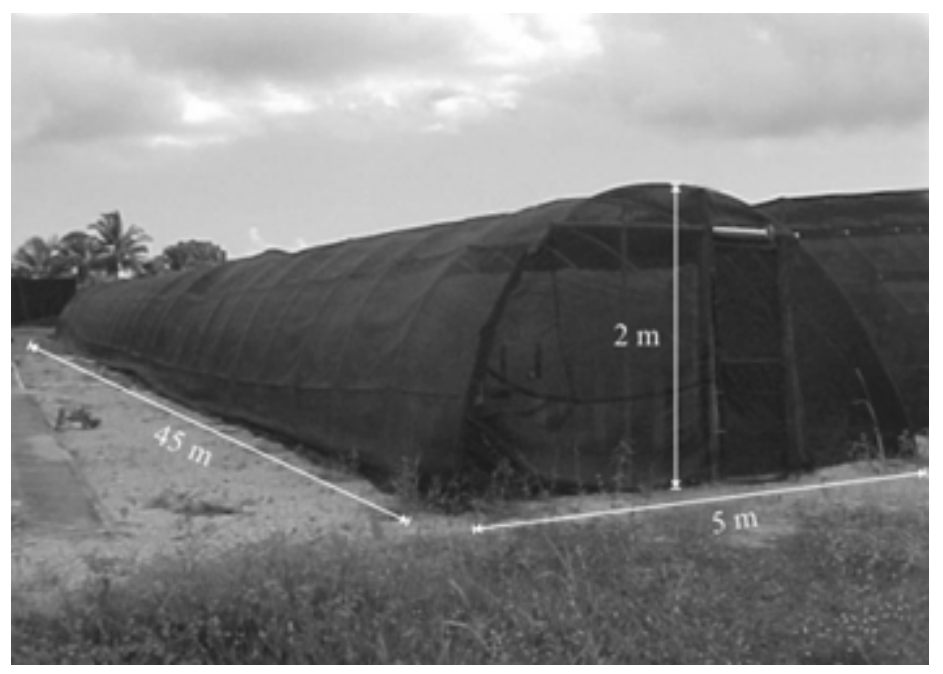

Figura 1. Telado da Embrapa Agroindústria Tropical, Fortaleza-CE, 2005.

Figure 1. Greenhouse of the Embrapa Tropical Agroindustry, Fortaleza-CE, 2005.
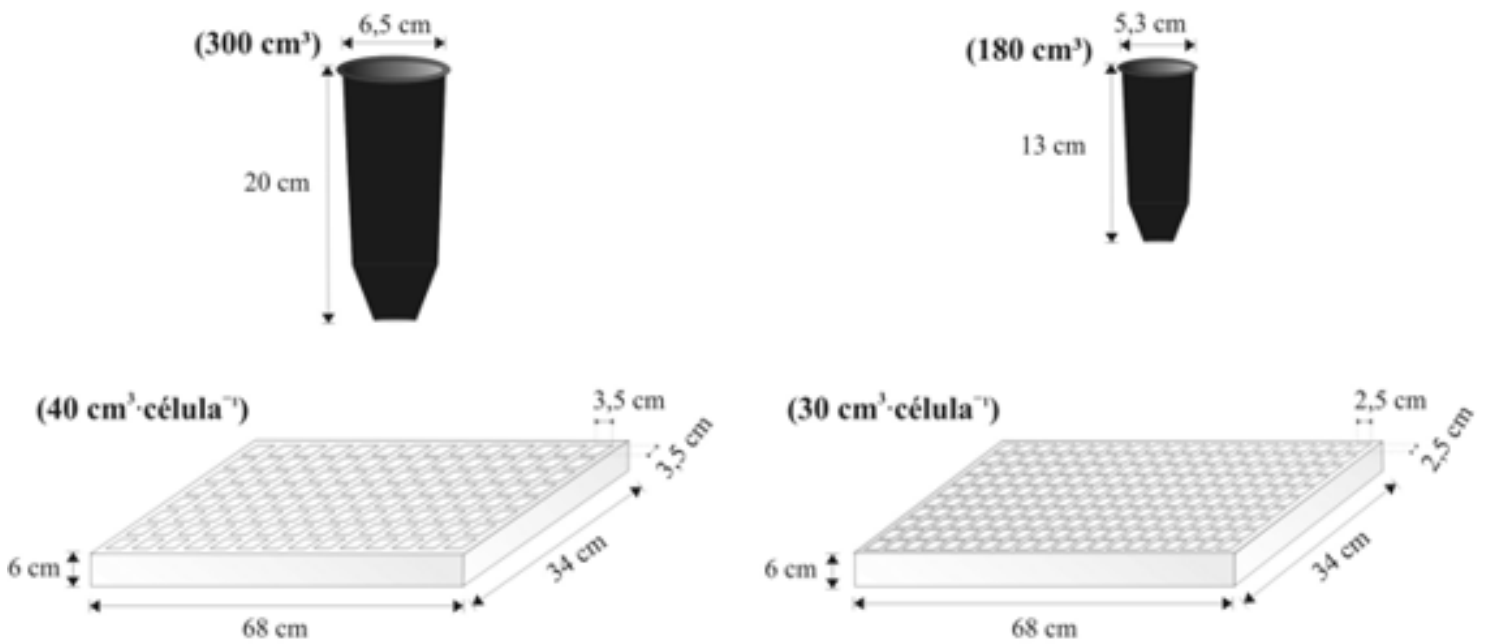

Figura 2. Tubete de $300 \mathrm{~cm}^{3}$, tubete de $180 \mathrm{~cm}^{3}$, bandeja de $40 \mathrm{~cm}^{3} \cdot$ célula $^{-1}$ e bandeja de $30 \mathrm{~cm}^{3} \cdot$ célula $^{-1}$, Fortaleza-CE, 2005 . Figure 2. Pot of $300 \mathrm{~cm}^{3}$, pot of $180 \mathrm{~cm}^{3}$, tray of $40 \mathrm{~cm}^{3} \cdot \mathrm{cell}^{-1}$ and tray of $30 \mathrm{~cm}^{3} \cdot$ cell $^{-1}$, Fortaleza-CE, 2005. 


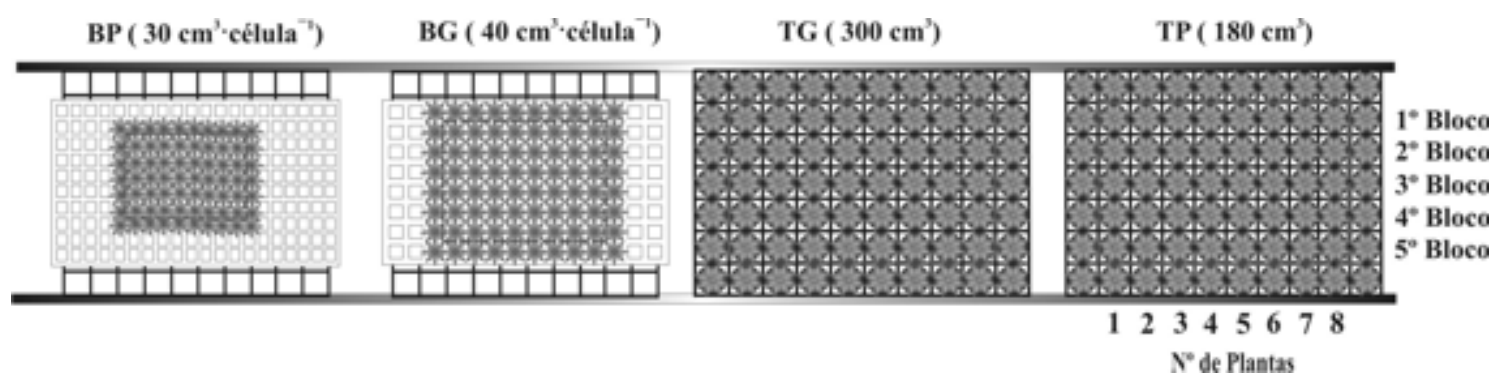

Figura 3. Disposição dos tratamentos no experimento volumes de substrato, Fortaleza-CE, 2005. Figure 3. Disposition of the treatments in the experiment substrate volumes, Fortaleza-CE, 2005.

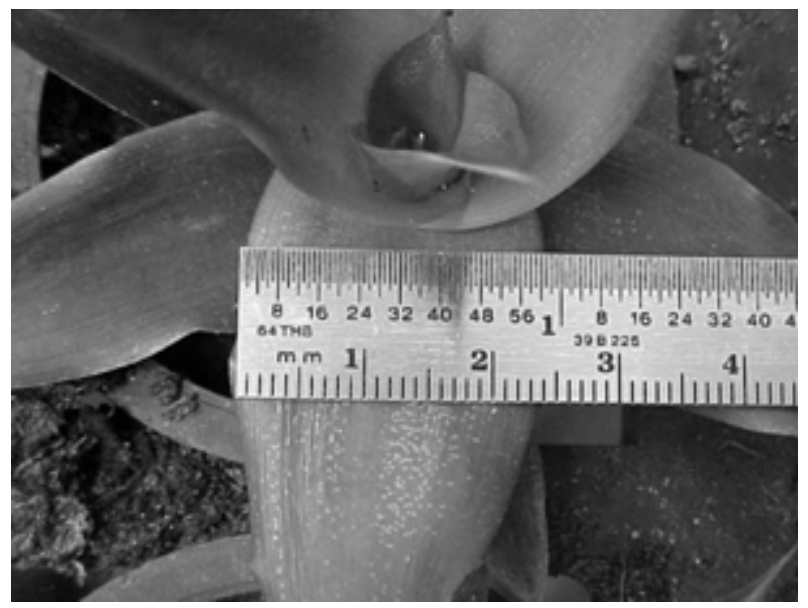

Figura 4. Medição da maior largura da $3^{\mathrm{a}}$ folha de abacaxizeiro ornamental (Ananas comosus var. erectifolius), Fortaleza-CE, 2005. Figure 4. Measurement of the largest width of the 3rd leaf of ornamental pineapple (Ananas comosus var. erectifolius), Fortaleza-CE, 2005.

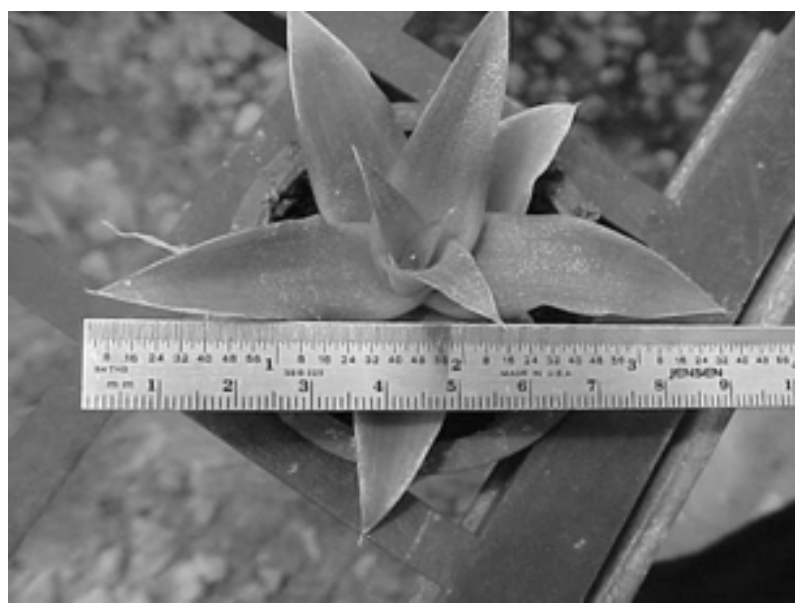

Figura 5. Medição do maior diâmetro da roseta de abacaxizeiro ornamental (Ananas comosus var. erectifolius), Fortaleza-CE, 2005. Figure 5. Measurement of the largest diameter of the rosette of ornamental pineapple (Ananas comosus var. erectifolius), FortalezaCE, 2005 . 